\title{
Socioeconomic status, health inequalities and non-communicable diseases: a systematic review
}

\author{
Santiago Lago ${ }^{1,2}$ - David Cantarero ${ }^{1,3} \cdot$ Berta Rivera $^{1,4}$ - Marta Pascual ${ }^{1,3}$. \\ Carla Blázquez-Fernández ${ }^{1,3}$ (D) $\cdot$ Bruno Casal $^{1,4} \cdot$ Francisco Reyes $^{1,2}$
}

Received: 23 May 2017 / Accepted: 25 September 2017 / Published online: 17 October 2017

(C) The Author(s) 2017. This article is an open access publication, corrected publication January/2018

\begin{abstract}
Aim A comprehensive approach to health highlights its close relationship with the social and economic conditions, physical environment and individual lifestyles. However, this relationship is not exempt from methodological problems that may bias the establishment of direct effects between the variables studied. Thus, further research is necessary to investigate the role of socioeconomic variables, their composition and distribution according to health status, particularly on noncommunicable diseases.

Subjects and methods To shed light on this field, here a systematic review is performed using PubMed, the Cochrane Library and Web of Science. A 7-year retrospective horizon was considered until 21 July 2017.

Results Twenty-six papers were obtained from the database search. Additionally, results from "hand searching" were also included, where a wider horizon was considered. Five of the
\end{abstract}

26 studies analyzed used aggregated data compared to 21 using individual data. Eleven considered income as a study variable, while 17 analyzed the effect of income inequality on health status ( 2 of the studies considered both the absolute level and distribution of income). The most used indicator of inequality in the literature was the Gini index.

Conclusion Although different types of analysis produce very different results concerning the role of health determinants, the general conclusion is that income distribution is related to health where it represents a measure of the differences in social class in the society. The effect of income inequality is to increase the gap between social classes or to widen differences in status.

Keywords Socioeconomic status $\cdot$ Health inequalities · Non-communicable diseases $\cdot$ Systematic review

\author{
Carla Blázquez-Fernández \\ carla.blazquez@unican.es \\ Santiago Lago \\ slagop@uvigo.es \\ David Cantarero \\ david.cantarero@unican.es \\ Berta Rivera \\ berta@udc.es \\ Marta Pascual \\ marta.pascual@unican.es \\ Bruno Casal \\ bcasal@udc.es
}

Francisco Reyes

francisco.reyes@uvigo.es

1 GEN Governance and Economics Network-Spain, Faculty of Business and Tourism University of Vigo, Campus Universitario As Lagoas s/n, 32004 Ourense, Spain

2 Department of Applied Economics, Faculty of Business and Tourism University of Vigo, Campus Universitario As Lagoas s/n, 32004 Ourense, Spain

3 Department of Economics, Faculty of Business and Economics University of Cantabria, Avda. de los Castros, S/N, 39005 Santander, Spain

4 Department of Applied Economics, Faculty of Business and Economics University of A Coruña, Campus de Elviña, 15071 A Coruña, Spain 


\section{Introduction}

From a broad point of view, an individual's health is considered not only an absence of disease, but also a fundamental human right (WHO 1986). A comprehensive approach to health highlights its close relationship with social and economic conditions, the physical environment and individual lifestyles. According to the Commission on Social Determinants of Health, we can consider health inequalities to be the result of the cumulative impact of decades of exposure to health risks of those who live in socioeconomically less advantaged circumstances (WHO 2008).

If we focus on all the socioeconomic variables, the relationship between income (understood as a measure of socioeconomic status) and health is probably the most complicated (Fuchs 2004). The correlation coefficient, obtained from the crudest associations, can range from highly positive to slightly negative, depending on the context and the aggregation level. Even when the positive correlation is strong and stable, causal interpretations may include income influencing health, health influencing income and/or "third variables" affecting both indicators in the same direction and at the same time. For this reason, the gross domestic product (GDP) is related to some health outcomes indicators (Kanavos and Mossialos 1996). However, there are exceptions. For example, some Southern countries in the European Union that are relatively poor have a life expectancy indicator greater than that of the rich countries of Northern Europe. Also, we can observe that the USA, one of the world's richest countries in terms of GDP per capita, has infant mortality rates similar to those of poorer countries (Starfield 2000).

In addition, there is a large and growing body of literature in which the effects of income on health are examined because of the importance of these effects in the development of appropriate economic policies (Gravelle et al. 2002). Many studies have shown a negative association between income and mortality (Lutter and Morrall 1994; McCarron et al. 1994; Viscusi 1994; Singh and Siahpush 2002; Shaw et al. 2005; Pearce and Dorling 2006; Leyland et al. 2007; Ezzati et al. 2008; Thomas et al. 2010). These empirical findings suggest that individual health is a function of individual income - the absolute income hypothesis. In relation to income inequality, the relative income-health hypothesis suggests that income inequality has a detrimental effect on population health because it is an individual's relative rather than absolute income that is important for health (Marmot et al. 1991; Wilkinson 1997, 1998; Wildman 2001, 2003; López I Casasnovas and Rivera 2002; Gravelle et al. 2002; Eberstadt and Satel 2004). Income inequality may therefore be a health risk (Le Grand 1987; Wilkinson 1992, 1996). Thus, life expectancy and population mortality have been used as key indicators of economic and social development (Van Doorslaer and Koolman 2004; Cantarero et al. 2005).
Although previous empirical literature presents different interpretations of the evidence, most analyses report that the average health is worse in more unequal societies. However, this relationship is not perfect, since there are several determinants that can affect it. There is clear evidence indicating that a nonlinear, typically concave relationship between health and income at an individual level will generate an aggregate relationship in which average health will depend negatively on the degree of inequality in the income distribution (Duleep 1995; Wilkinson 1996; Mackenbach et al. 2005; Mackenbach 2012). Hence, income redistribution from the rich to disadvantaged groups may improve some health indicators (Kawachi and Kennedy 1999). Also, some authors have suggested the existence of conceptual difficulties in studying the relationship between income and individual health when aggregated data are used, because revenues have a diminishing marginal effect on health (Deaton and Muellbauer 1980). This is because if income inequality increases, it tends to reduce average health but improve the health of "the rich," although this latter effect is less significant than the reduction in overall health.

\section{Methods}

A systematic literature search was performed in PubMed, the Cochrane Library and Web of Science (until 21 July 2017) to identify the most relevant published evidence regarding the relationship between income and health. In all databases, terms related to "health," "income" and "inequalities" were combined. See Appendix Table 4 for the search strategy/search terms used. The searches were confined to papers published in the English language since 2010 to limit the scope of this review to the most recent data and the state of the art. In other words, we considered this retrospective horizon, from the beginning of this century up to date, to be enough.

\section{Results}

After finding publications in the electronic searches, duplicate records were removed. The selection of papers was ultimately based on the following eligibility criterion: an applied study with a focus on one or more OECD countries (including the European Union and other developed countries). Additionally, the results of "hand searching" were also included in the following pages, where a wider horizon was considered. Figure 1 is a diagram of the paper selection process.

The literature search located 381 publications in the databases under consideration, and 17 papers published 

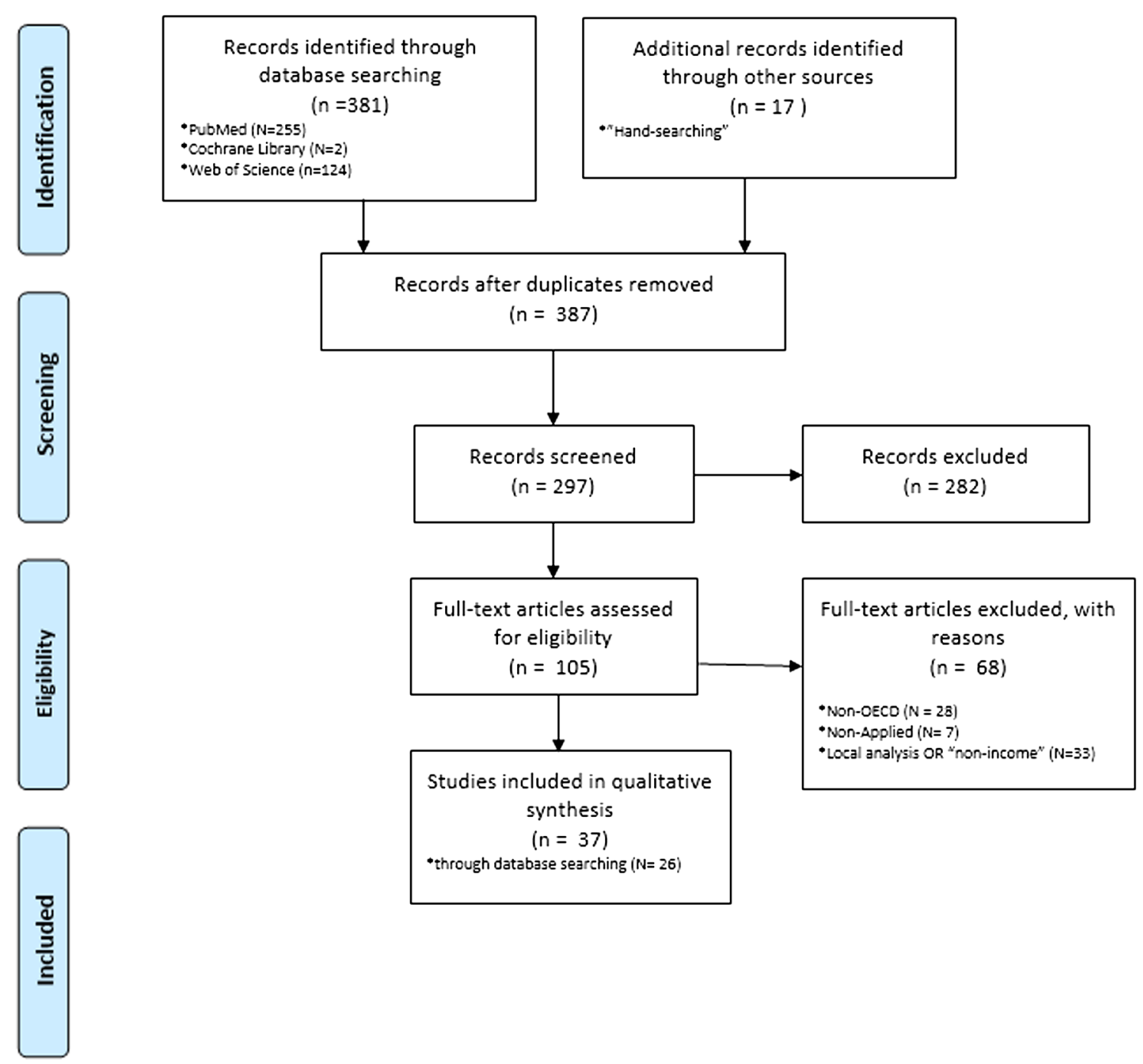

Fig. 1 Flow diagram of the paper selection process. The flow diagram depicts the different phases (identification-screening-eligibility-included) of the systematic review. It maps out the number of records in each phase and shows how many studies were included or excluded, respectively

between 2010 and 2017 were identified through "hand searching." A total of 11 duplicates were removed, resulting in 387 "unique papers." After screening the titles against the eligibility criteria, 105 papers were selected. Of these, 68 articles were excluded as they did not fit the previous criteria. So, a final set of 37 selected studies were taken into account in this review, and further papers were finally considered to have a robust overview. Table 1 focuses on the 26 papers found in the database search.

We also reviewed the works obtained from "hand searching," where the results are almost all based on economic criteria. Specifically, we can highlight that there is also much evidence for the effect of income on health status for different socioeconomic groups. References are listed at the end of this article, and we included references in journals and cited books.
Table 1 focuses on the 26 papers obtained from the database search. The first group of studies explores the fact that people who live in areas of high inequalities tend to report themselves as having both an objective (having a shorter life expectancy and high adult mortality) and subjective health status and that this tendency increases over time (Allanson et al. 2010; Elgar 2010; Huijts et al. 2010; Idrovo et al. 2010; Islam et al. 2010; Karlsson et al. 2010; Oshio and Kobayashi 2010; Petrie et al. 2011). Moreover, the following group of studies developed various econometric approaches (multilevel regression, bivariate and count data or logit models) to consider geographic, socioeconomic and poverty-related issues (Chen and Crawford 2012; Hosseinpoor et al. 2012; Karlsdotter et al. 2012; Martinson 2012; Allanson and Petrie 2013; Ásgeirsdóttir and Ragnarsdóttir 2014; Wilson et al. 2017). The health concentration index and its corrections have been employed 


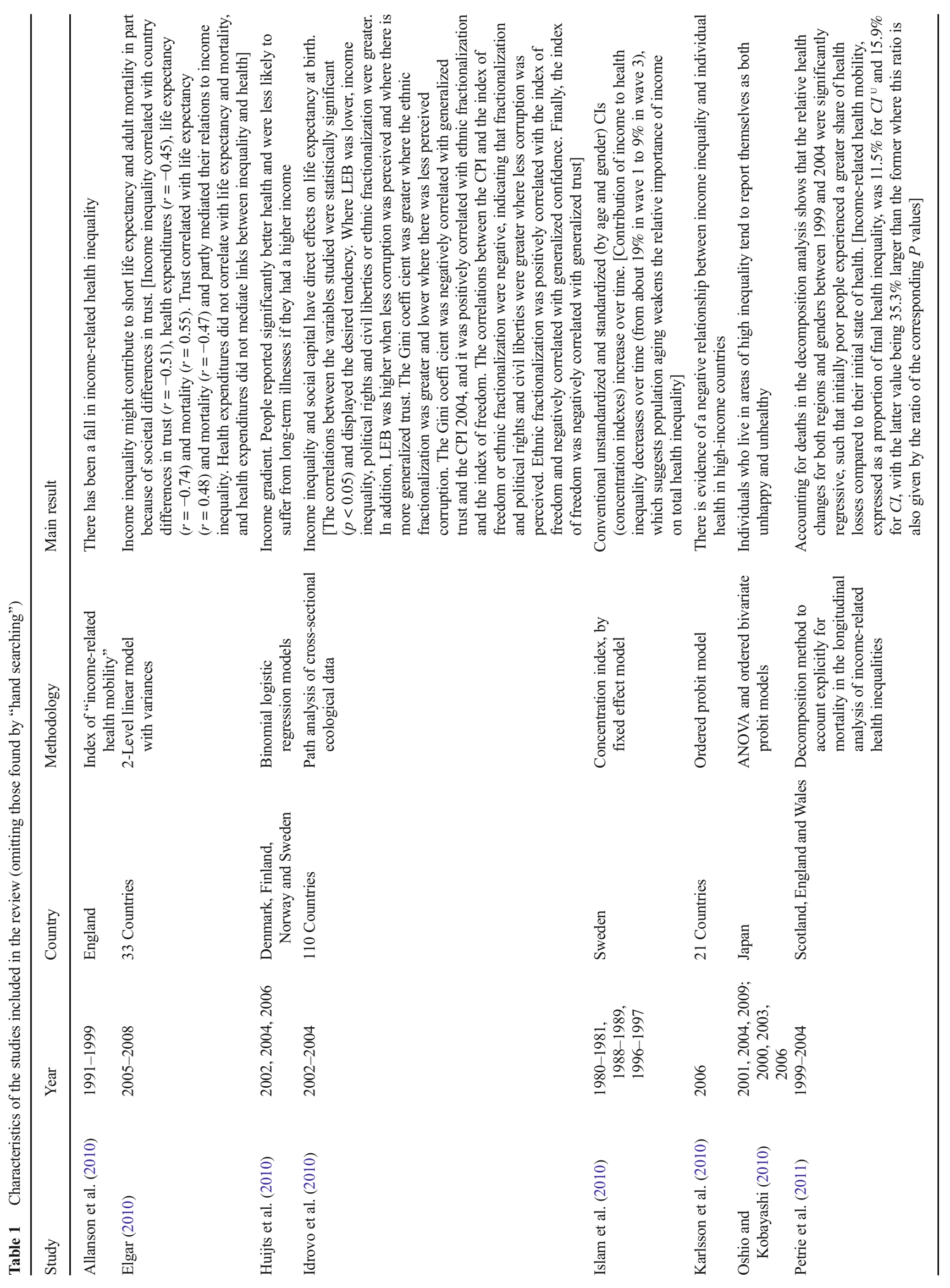




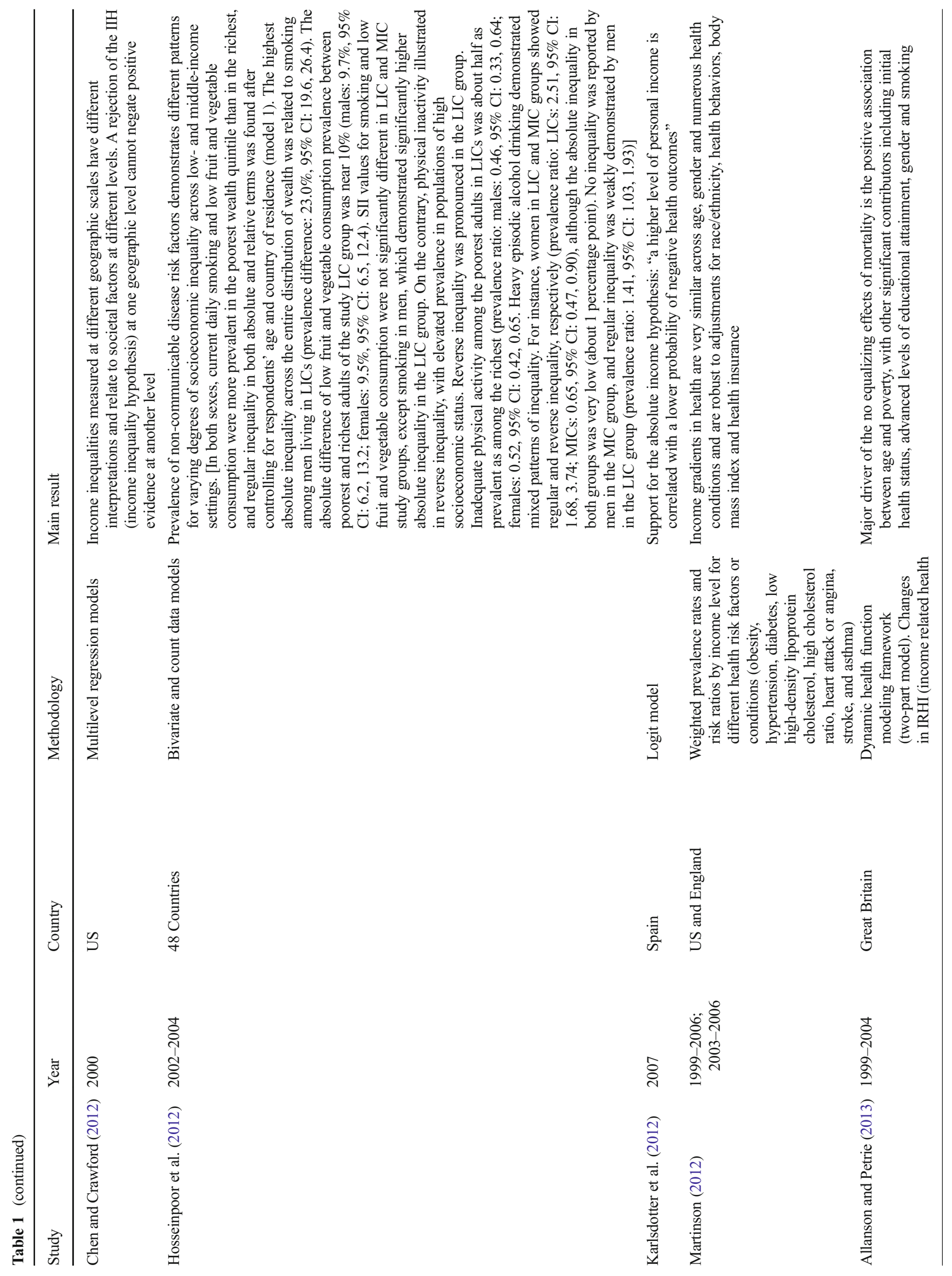




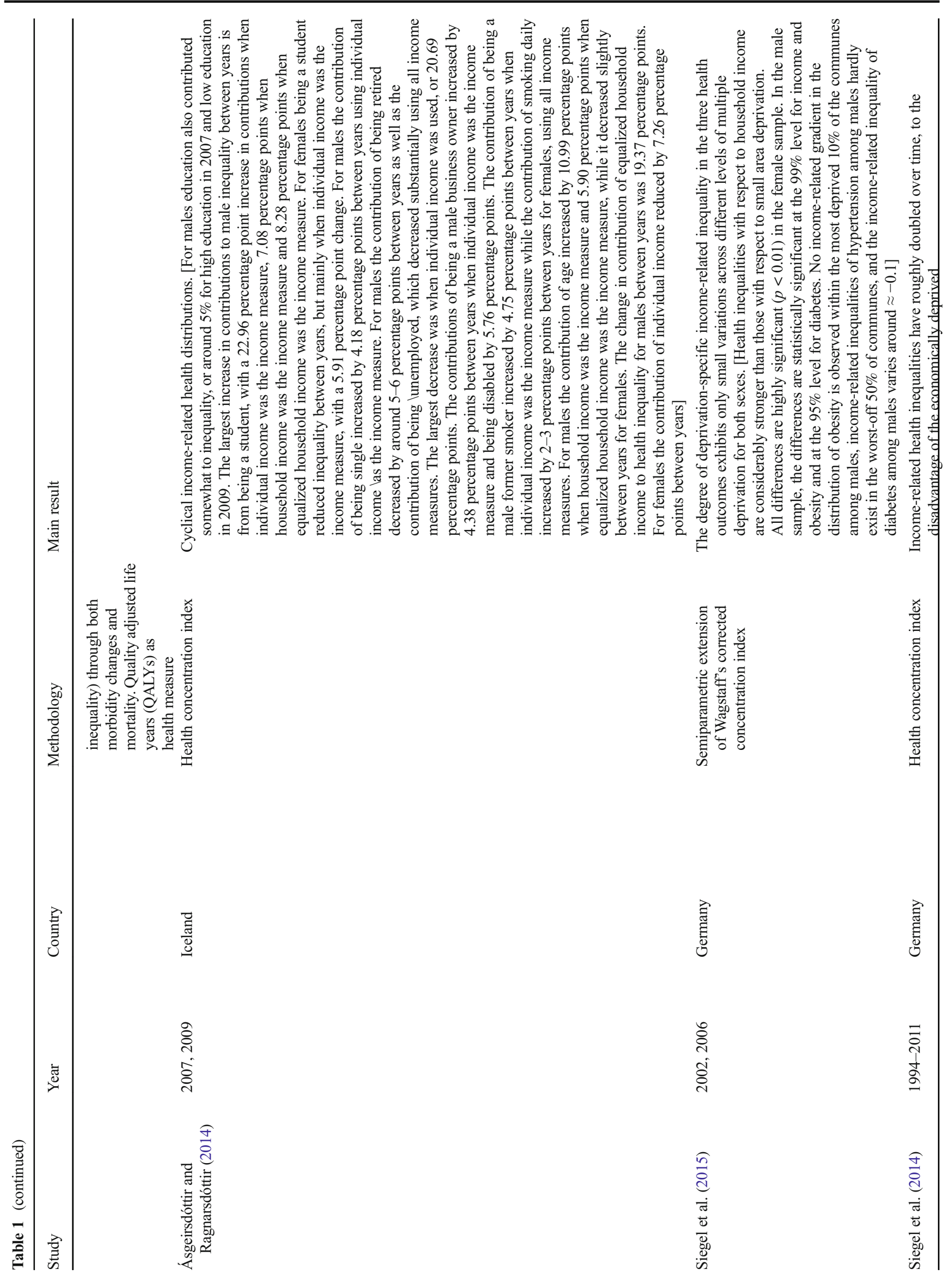




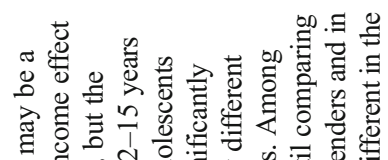

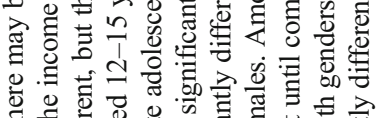

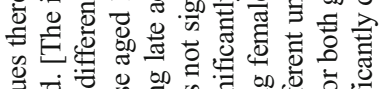
它:

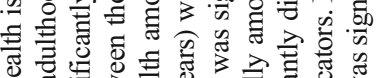

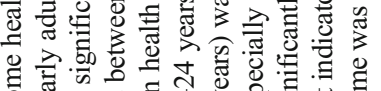

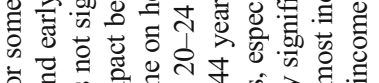

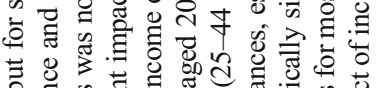

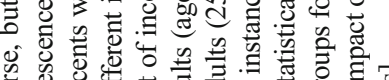

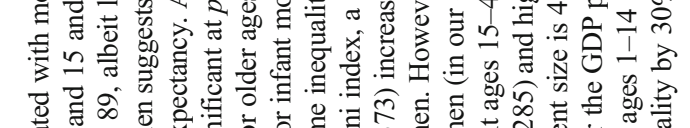

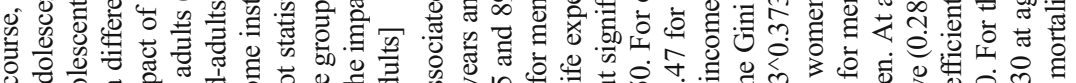

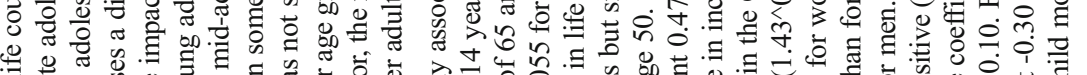

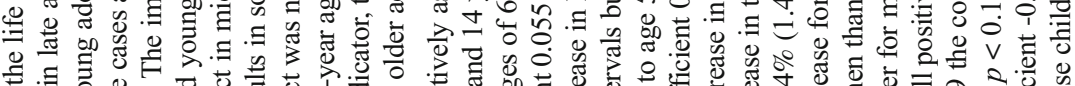

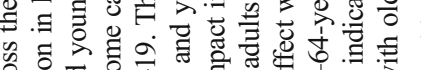

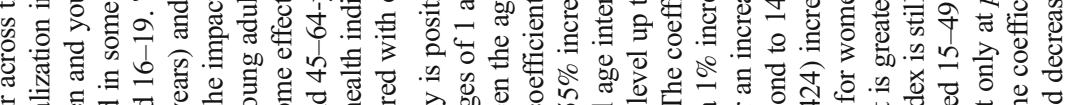

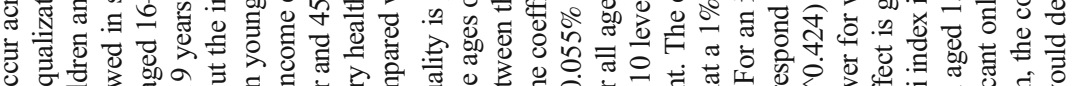

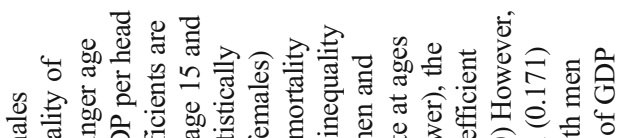

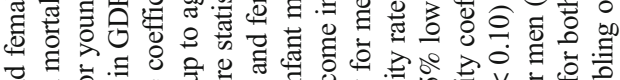

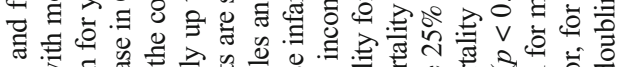

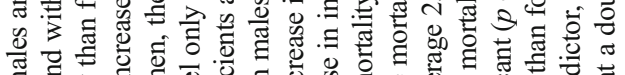

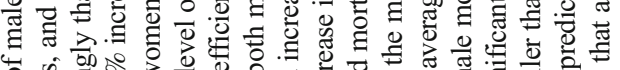

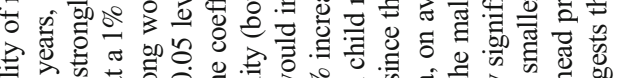

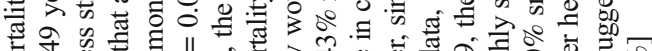

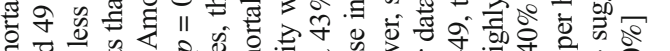

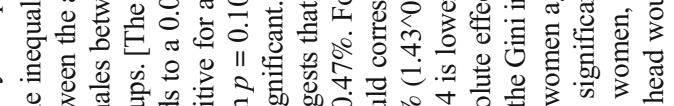

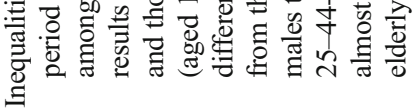

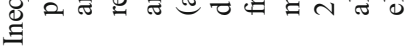
ठํ. 茄要

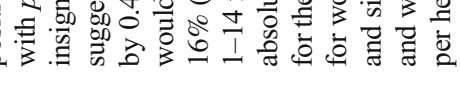


in recent studies (Siegel et al. 2014; Vallejo-Torres et al. 2014; Siegel et al. 2015). As described in Table 1 and Fig. 2 , the relative income-health hypothesis was also analyzed by $\mathrm{Hu}$ et al. (2015), who conclude that in European countries income inequality does not have an independent effect on mortality.

Moreover, it seems logical that there would be a difference between rich and poor countries in how income distribution would affect health status (Waldmann 1992; Rodgers 1979; Deaton 2001b). Wilkinson and Pickett (2006) performed a review of the literature analyzing the association between the income distribution and health of the population. The general conclusion is that income distribution is related to health where it represents a measure of the differences in social class in the society.

Among the studies conducting their analysis on individual data, Ettner (1996) estimates the effects of income on a set of individual health proxies. The results show a strong positive effect of income on health. Dahl et al. (2006) analyzed the degree to which contextual income inequality affects the health in Norwegian regions; the results differ from previous studies in suggesting that in Norway a comparatively egalitarian income distribution interferes with the emergence of regional-level income inequality effects on mortality. From another point of view, a study developed in Spain (Regidor et al. 2014) showed that inequality in the distribution of provincial income declined during the 4 decades covered by the study. More recently, Pickett and Wilkinson (2015) conducted a new review of the literature on the subject, exploring the causal role of wider income differences in health. The authors highlight that the effect of income inequality is to increase the gap between social classes or to widen differences in socioeconomic status.

As Table 2 shows in relation to health indicators, measuring the health status of a population is problematic because there is no complete and comparable health index among countries or regions.

Data aggregation, used in numerous studies examining the health status of the population in different countries and its relationship to the level of income, can also present problems from a methodological point of view. The first problem is the availability of comparable data for long periods of time. The observations are often measures at the national or regional level, in contrast to individual panel data for which there are many observations of cross-sectional measurements at very few points in time. Therefore, the problems differ depending on the observation unit adopted: the individual or an aggregated geographical area.

Causality of the variables that are considered in the analysis of the relationship between income and health is another methodological aspect that is particularly relevant (Fuchs 2004). Although numerous studies indicate a positive relationship 
Fig. 2 Relative and absolute income-health hypotheses
Income inequality and health

The absolute income hypothesis states that the higher an individual's income, the better is their health, holding other factors constant. References: Preston (1975), Adler et al. (1993), Pritchett and Summers (1996). Thus, individual health is a function of individual income.

The relative income hypothesis states that in developed countries an individual's health is also affected by the distribution of income within societyReferences: Kaplan et al. (1996), Kennedy et al. (1996), Wilkinson (1997), Torre and Myrskylä (2014).

In developed countries income inequality has a larger impact on individual health than absolute income.

Both hypotheses have been tested. The studies suggest that reducing inequality is good for the health of the whole population and not only for the health of those individuals with the lowest incomes.

However an aggregation problem can be detected, as other authors have shown (Waldmann 1992; Gravelle et al. 2002; Wildman 2003; Mackenbach et al. 2005). between health and income, few of them analyze the causality of this association. The stability of income inequality over time in most countries makes this causality difficult to test (Babones 2008). This author points out that although there exist a "strong, consistent and statistically significant correlation between national income inequality and population health," there is also evidence indicating that this correlation is causal.

McKeown (2009) describes changing patterns of population age distributions, mortality, fertility, life expectancy and causes of death. However, within countries, differences in living standards establish a social order in the population. Among the papers that raise the issue of income distribution as a possible reason for inequalities in individuals' health, that published by Deaton (1999) is notable. Furthermore, Deaton and Paxson (2001) develop a similar analysis to examine the relationship between income inequality and mortality. The results show that neither the trends in the level of income nor the inequalities in income explain the adjusted mortality rates by age. Besides, Wagstaff and Van Doorslaer (2000) review a large body of literature on the effects of income inequality on population health. The literature review shows that the individual level studies considered to be relevant provide strong support for the absolute income hypothesis, no support for the relative income hypothesis and little or no support for the income inequality hypothesis. In relation to this, we can think about the countries of Eastern Europe, where, despite their egalitarian distribution of income, there are high mortality rates. Contoyannis and Foster (1999) found that it is absolute income that has a significant effect on health, not relative income. Along the same lines, we can point to the paper of Van Doorslaer et al. (1997), whose results support the idea that health inequalities cannot be definitively attributed to income inequalities.
Table 2 Health indicators, data aggregation and causality of variables (income and health)
Health indicators

Data aggregation

Causality of the variables
There is no complete and comparable health index for all countries. The indicators commonly used are mortality rates (infant and adult) and life expectancy. However, these indicators are not sensitive to improvements in quality of life (Parkin et al. 1987). Data at the individual level are recommended (Wagstaff and Van Doorslaer 2000)

This presents problems from a methodological point of view. The availability of comparable data for long periods of time is a problem, and individual conditions of linearity are required, while the evidence suggests that relationships in this regard are configured in a nonlinear way (Preston 1975; Rodgers 1979; Duleep 1995; Ettner 1996; Deaton 2001a, 2001b; Gravelle et al. 2002; Mackenbach et al. 2005)

Population health would also help explain differences in income levels among individuals and countries. The effect could bias results and make any inferences about the structural effect of income on health difficult (Fuchs 1974, 2004; Ettner 1996) 
Table 3 Social mobility over the life course: some findings
Recent papers

Some empirical findings
Currie and Madrian (1999), Bengtsson and Mineau (2009), Almond and Currie (2011), De Ree and Alessie (2011), Lundborg et al. (2014), Flores et al. (2015)

Inequalities in health and socioeconomic status are present early in life

Childhood circumstances have direct and indirect impacts (through mediating determinants) on health in later life and on outcomes related to socioeconomic status [mainly understood as employment (or educational level) and wages]

The most efficient way (universal vs. group-specific interventions) to solve life cycle inequalities in health and socioeconomic status is an open question

Alternative specifications should be used for the model, or long panels should be used to follow the same individuals over a period of time, as their age could help to understand the impact of health on socioeconomic status and to predict future health and the expenditure required
Also, as Table 3 describes, the trajectories of social mobility over the life course (U-shaped) and the variations in patterns of social mobility mean that it is very important to study inequalities in health and socioeconomic status because they are present early in life (Currie and Madrian 1999; Bengtsson and Mineau 2009; Almond and Currie 2011; Currie and Almond 2011; De Ree and Alessie 2011; Lundborg et al. 2014).

Furthermore, it would be interesting to take into account the existing links between parental socioeconomic status (measured by education, income or labor status) and child health and therefore between the health of a child today and his or her health and status in the future (its derived results in education, income and/or adult occupation) (Currie and Madrian 1999; Aizer and Currie 2014; Fletcher 2014; Flores and Kalwij 2014; Flores et al. 2015).

\section{Discussion}

In this article we analyze the literature that studies the determinants of health with special attention to the relationship between socioeconomic status and health status. The socioeconomic status will be approached through different indicators, mainly income. To do so, we first discuss relevant articles in this field, which are among the most cited by literature, and then focus on a systematic literature review of recent years. In the revised literature, 5 of the 26 studies analyzed use aggregated data (19\%) compared to 21 using individual data $(81 \%)$. Most of them analyze the effect of income inequality on health status (17) in comparison with the 11 studies that consider income as a main variable of the study ( 2 of the studies consider both the absolute level of income and the distribution of income). The indicator of inequality most used in the literature is the Gini index.

The revised literature shows that people who live in areas of high inequalities tend to have a shorter life expectancy and high adult mortality and that this tendency increases over time. Among the studies that conduct their analysis on individual data, the results show a strong positive effect of income on health. The effect is particularly relevant in areas of high inequalities, and its influence can be observed from different socioeconomic measures (education, income, labor status).

Findings vary according to the type of study if the individual age is considered. In this sense, we find articles that show that individuals are statistically more likely to report poorer health if they were more unequally distributed during the first years of their lives than at an advanced age. However, other studies find that the magnitude of health inequalities is not consistent across age groups. For the income level, most of the results find that the major driver of the disequalizing effects of mortality is the positive association between old age and poverty.

There is also an interest in solving the apparent paradox that income appears to be related to health within countries but not between them. The explanation relies on the fact that in developed countries, which have already achieved a certain standard of living, increases in per capita GDP have little effect on the levels of health because of the epidemiological transition (understood under the fourth proposition by Omran (1971, 1982): "The shifts in health and disease patterns that characterize the epidemiologic transition are closely associated with the demographic and socioeconomic transition that constitute the modernization complex"), as in addition to epidemiological changes or changes in health conditions, the health transition also incorporates related social changes as a health care transition, as has been shown, for example, by Karlsson et al. (2010), Petrie et al. (2011), Hosseinpoor et al. (2012) and Siegel et al. (2014).

However, population health would also help to explain differences in income levels between individuals and between countries. The importance of investment in health has been re-emphasized by the theories of human capital. Improvements in health diminish productivity losses caused by disease in the workforce, reducing disability, weakness and the number of days off work. Also, they increase assistance to schools and the learning capacity of 
school children. One could also point to the decline of family disruption and other undesirable social issues as well as the reduction of negative externalities, for example, in the case of caring for the sick.

The effects of productivity gains in workers are particularly great for countries with a low level of development. Poor people have a higher risk of illness, and their income depends exclusively on their physical work. Investment in health would therefore be a productive investment, since it would increase income. It would be an important part of development and would help to reduce the income gap between rich and poor countries. Testing this relationship may lead to inconsistencies because of the causality between the two variables. This reverse causality could bias the results and make it difficult to draw inferences about the structural effect of income on health.

Finally, there are some limitations to this review we should consider. First, the literature search was limited to the main (three) databases. Future systematic reviews could also include other relevant sources. Second, the findings were not weighted for sample size.

\section{Conclusion}

The published health economics literature on socioeconomic status, health and non-communicable diseases is characterized by many papers showing the complexity of those relationships. Improving this information is crucial if we are to capture the value of socioeconomic measures fully and to discover the most relevant determinants of health and noncommunicable diseases.

From the literature analysis, we can conclude that income inequality was associated with worse average health. These results remain practically coincident regardless of the health indicator considered. The main conclusion of the studies analyzing the temporal evolution of both variables is that income inequalities in health increase over time to the detriment of the economically disadvantaged.

What is true is that different types of analysis produce very different results on the role of health determinants. Thus, the individual conception of health provides a different framework of research from a social analysis. The differences are relevant when the results are presented in terms of effectiveness in health policies and welfare (Wildman 2003). Although the determinants of health identified in individual studies are important variables in an aggregate analysis, there are specific factors that affect social groups. In this sense, for example, a better health status derived from a greater level of education may be the result of an education variable directly influencing the individual's health or may be because of an improvement in social class due to a better education.
Finallly, further research is necessary to investigate the role of income level, its composition and its distribution in health status and the labor market. To help with this, perhaps we can highlight the greater potential of individual studies, with the new databases available, for analyzing hypotheses about a more detailed relationship among socioeconomic status, health and non-communicable diseases.

Authors' contribution All authors developed the idea for the systematic review and contributed to the concept and design. All authors contributed to the writing of the manuscript and read and approved the final manuscript. The materials have not been submitted to other journals.FundingThe paper is part of the research involved in the project "FRESHER-Foresight and Modelling for European Health Policy and Regulation" funded by the European Commission through the Horizon 2020 Framework under grant agreement no. 643,576 . The sole responsibility for the content of this project lies with the authors. It does not necessarily reflect the opinion of the European Union. The European Commission is not responsible for any use that may be made of the information contained therein.

\section{Compliance with ethical standards}

Ethics approval and consent to participate Not applicable.

Availability of data and material Not applicable.

Competing interest The authors declare that they have no competing interest.

\section{Appendix}

Table 4 Search strategy: PubMed, Cochrane Library and Web of Science

\begin{tabular}{ll}
\hline$\#$ & Search term \\
\hline PubMed \\
$\# 1$ & Health [title/abstract] \\
$\# 2$ & Income [title/abstract] \\
$\# 3$ & Inequality [title/abstract] \\
$\# 4$ & Limit to: journal article; year of publication $\geq 2010 ;$ \\
& $\quad$ English and Spanish; Humans subjects, free-full text \\
Cochrane Library \\
$\# 1$ & Health [title/abstract] \\
$\# 2$ & Income [title/abstract] \\
$\# 3$ & Inequality [title/abstract] \\
$\# 4$ & Limit to: year of publication $\geq 2010$. \\
Web of Science \\
$\# 1$ & Health [topic]; [title] \\
$\# 2$ & Income [topic]; [title] \\
$\# 3$ & Inequality [topic]; [title] \\
$\# 4$ & Limit to: journal article; year of publication $\geq 2010 ;$ \\
& English and Spanish; Public Environmental Occupational \\
& Health "or" Social Issues "or" Health Care Sciences Services \\
\hline
\end{tabular}


Open Access This article is distributed under the terms of the Creative Commons Attribution 4.0 International License (http:// creativecommons.org/licenses/by/4.0/), which permits unrestricted use, distribution, and reproduction in any medium, provided you give appropriate credit to the original author(s) and the source, provide a link to the Creative Commons license, and indicate if changes were made.

\section{References}

Adler NE, Boyce WT, Chesney MA, Folkman S, Syme SL (1993) Socioeconomic inequalities in health: no easy solution. JAMA 269(24):3140-3145

Aizer A, Currie J (2014) The intergenerational transmission of inequality: Maternal disadvantage and health at birth. Science 344(6186):856861

Allanson P, Petrie D (2013) Longitudinal methods to investigate the role of health determinants in the dynamics of income-related health inequality. J Health Econ 32(5):922-937

Allanson P, Gerdtham UG, Petrie D (2010) Longitudinal analysis of income-related health inequality. J Health Econ 29(1):78-86

Almond D, Currie J (2011) Killing me softly: The fetal origins hypothesis. J Econ Perspect 25(3): 153-172

Ásgeirsdóttir TL, Ragnarsdóttir DÓ (2014) Health-income inequality: the effects of the Icelandic economic collapse. Int J Equity Health 13(1):50

Babones SJ (2008) Income inequality and population health: correlation and causality. Soc Sci Med 66(7):1614-1626

Bengtsson T, Mineau GP (2009) Early-life effects on socio-economic performance and mortality in later life: a full life-course approach using contemporary and historical sources. Soc Sci Med 68(9): 1561-1564

Cantarero D, Pascual M, Sarabia JM (2005) Effects of income inequality on population health: new evidence from the European Community Household Panel. Appl Econ 37(1):87-91

Chauvel L, Leist AK (2015) Socioeconomic hierarchy and health gradient in Europe: the role of income inequality and of social origins. Int J Equity Health 14(1):1

Chen Z, Crawford CA (2012) The role of geographic scale in testing the income inequality hypothesis as an explanation of health disparities. Soc Sci Med 75(6):1022-1031

Contoyannis P, Foster M (1999) The distribution of health and income: a theoretical framework. J Health Econ 8:605-662

Currie J, Almond D (2011) Human capital development before age five. Handbook of labor Economics 4:1315-1486

Currie J, Madrian BC (1999) Health, health insurance and the labor market. Handbook of labor Economics 31 3:3309-3416

Dahl E, Elstad JI, Hofoss D, Martin-Mollard M (2006) For whom is income inequality most harmful? A multi-level analysis of income inequality and mortality in Norway. Soc Sci Med 63(10):2562-2574

De Ree J, Alessie R (2011) Life satisfaction and age: dealing with underidentification in age-period-cohort models. Soc Sci Med 73(1):177-182

Deaton A (1999) Inequalities in income and inequalities in health. NBER Working Paper W7141

Deaton A (2001a) Relative deprivation, inequality, and mortality. NBER Working Paper W8099

Deaton A (2001b) Health, inequality, and economic development. NBER Working Paper W8318

Deaton A, Muellbauer J (1980) Economics and Consumer Behaviour. Cambridge University Press, Cambridge
Deaton A, Paxson C (2001) Mortality, income, and income inequality over time in Britain and the United States. NBER Working Paper W7140

Duleep JO (1995) Mortality and income inequality among economically developed countries. Soc Secur Bull 58(2):35-40

Eberstadt N, Satel SM (2004) Health and the income inequality hypothesis. A doctrine in search of data. The American Enterprise Institute Press, Washington, D.C.

Elgar FJ (2010) Income inequality, trust, and population health in 33 countries. Am J Public Health 100(11):2311-2315

Ettner SL (1996) New evidence on the relationship between income and health. J Health Econ 15:67-85

Ezzati M, Friedman AB, Kulkarni SC, Murray CJL (2008) The reversal of fortunes: trends in county mortality and cross-county mortality disparities in the United States. PLoS Med 5:e66

Fletcher JM (2014) The effects of childhood ADHD on adult labor market outcomes. Health Econ 23(2):159-181

Flores M, Kalwij A (2014) The associations between early life circumstances and later life health and employment in Europe. Empir Econ 47(4):1251-1282

Flores M, Garcia-Gomez P, Kalwij A (2015) Early life circumstances and life cycle labor market outcomes. Tinbergen Institute DP:04/V

Fuchs V (1974) Some economic aspects of mortality in developed countries. In: Perlman (ed) The economics of health and medical care. M Stockton Press, New York

Fuchs V (2004) Reflections on the socio-economic correlates of health. J Health Econ 23:653-661

Gravelle H, Wildman J, Sutton M (2002) Income, income inequality and health: what can we learn from aggregate data? Soc Sci Med 54: 577-589

Hosseinpoor AR, Bergen N, Kunst A, Harper S, Guthold R, Rekve D, d'Espaignet ET, Naidoo N, Chatterji S (2012) Socioeconomic inequalities in risk factors for non communicable diseases in lowincome and middle-income countries: results from the World Health Survey. BMC Public Health 12(1):1

$\mathrm{Hu}$ Y, van Lenthe FJ, Mackenbach JP (2015) Income inequality, life expectancy and cause-specific mortality in 43 European countries, 1987-2008: a fixed effects study. Eur J Epidemiol 30(8): 615-625

Huijts T, Eikemo TA, Skalická V (2010) Income-related health inequalities in the Nordic countries: examining the role of education, occupational class, and age. Soc Sci Med 71(11):1964-1972

Idrovo AJ, Ruiz-Rodríguez M, Manzano-Patiño AP (2010) Beyond the income inequality hypothesis and human health: a worldwide exploration. Rev Saude Publica 44(4):695-702

Islam MK, Gerdtham UG, Clarke P, Burström K (2010) Does incomerelated health inequality change as the population ages? Evidence from Swedish panel data. Health Econ 19(3):334-349

Jutz R (2015) The role of income inequality and social policies on income-related health inequalities in Europe. Int $\mathrm{J}$ Equity Health 14(1): 1

Kanavos P, Mossialos E (1996) The methodology of international comparisons of health care expenditures: any lessons for health policy? LSE Health Discussion Paper 3, London

Kaplan GA, Pamuk ER, Lynch JW, Cohen RD, Balfour JL (1996) Inequality in income and mortality in the United States: analysis of mortality and potential pathways. BMJ 312(7037):999-1003

Karlsdotter K, Martín JJ, del Amo González MP (2012) Multilevel analysis of income, income inequalities and health in Spain. Soc Sci Med 74(7):1099-1106

Karlsson M, Nilsson T, Lyttkens CH, Leeson G (2010) Income inequality and health: Importance of a cross-country perspective. Soc Sci Med 70(6):875-885

Kawachi I, Kennedy BP (1999) Income inequality and health: pathways and mechanisms. Health Serv Res 34:215-227 
Kennedy BP, Kawachi I, Prothrow-Stith D (1996) Income distribution and mortality: cross sectional ecological study of the Robin Hood index in the United States. BMJ 312(7037):1004-1007

Kim D (2016) The associations between US state and local social spending, income inequality, and individual all-cause and cause-specific mortality: the National Longitudinal Mortality Study. Prev Med 84:62-68

Le Grand J (1987) Inequalities in Health: some international comparisons. Eur Econ Rev 31:182-191

Leyland AH, Dundas R, McLoone P, Boddy FA (2007) Cause-specific inequalities in mortality in Scotland: two decades of change a population-based study. BMC Public Health 7(1):112

Lillard DR, Burkhauser RV, Hahn MH, Wilkins R (2015) Does early-life income inequality predict self-reported health in later life? Evidence from the United States. Soc Sci Med 128:347-355

López I Casasnovas G, Rivera B (2002) Las políticas de equidad en salud y las relaciones entre renta y salud. Hacienda Pública Española 161: 99-126

López DB, Loehrer AP, Chang DC (2016) Impact of income inequality on the nation's health. J Am Coll Surg 223(4):587-594

Lundborg P, Nystedt P, Rooth DO (2014) Height and earnings: the role of cognitive and noncognitive skills. J Hum Resour 49(1):141-166

Lutter R, Morrall J (1994) Health-health analysis: a new way to evaluate health and safety regulation. J Risk Uncertain 8(1):43-66

Mackenbach JP (2012) The persistence of health inequalities in modern welfare states: the explanation of a paradox. Soc Sci Med 75(4): 761-769

Mackenbach JP, Martikainen P, Looman CW, Dalstra JA, Kunst AE, Lahelma E, SEdHA Working Group (2005) The shape of the relationship between income and self-assessed health: an international study. Int J Epidemiol 34:286-293

Marmot M, Smith G, Stansfield S, Patel C, Nort F, Head J, White I, Brunner E, Feeny A (1991) Health inequalities among British civil servants: the Whitehall II study. Lancet 337(8754):1387-1393

Martinson ML (2012) Income inequality in health at all ages: a comparison of the United States and England. Am J Public Health 102(11): 2049-2056

McCarron PG, Davey Smith G, Womersle J (1994) Deprivation and mortality in Glasgow: increasing differentials from 1980 to 1992. BMJ 309:1481-1482

McKeown RE (2009) The epidemiologic transition: changing patterns of mortality and population dynamics. Am J Lifestyle Med 3:19S-26S

Omran AR (1971) The epidemiologic transition: a theory of the epidemiology of population change. Milbank Mem Fund Q 29:509-538

Omran AR (1982) Epidemiologic transition. In: Ross JA (ed) International encyclopedia of population. The Free Press, London, pp 172-183

Oshio T, Kobayashi M (2010) Income inequality, perceived happiness, and self-rated health: evidence from nationwide surveys in Japan. Soc Sci Med 70(9):1358-1366

Parkin D, McGuire A, Yule B (1987) Aggregate health care expenditures and national income: is health care a luxury good? J Health Econ 6(2):109-127

Pearce J, Dorling D (2006) Increasing geographical inequalities in health in New Zealand 1980-2001. Int J Epidemiol 35:597-603

Petrie D, Allanson P, Gerdtham UG (2011) Accounting for the dead in the longitudinal analysis of income-related health inequalities. J Health Econ 30(5):1113-1123

Pickett KE, Wilkinson RG (2015) Income inequality and health: a causal review. Soc Sci Med 128:316-326

Preston S (1975) The changing relation between mortality and level of economic development. Popul Stud 29:231-248

Pritchett L, Summers LH (1996) Wealthier is healthier. J Hum Resour 31: $841-868$
Quon EC, McGrath JJ (2015) Province-level income inequality and health outcomes in Canadian adolescents. J Pediatr Psychol 40(2): 251-261

Rambotti S (2015) Recalibrating the spirit level: an analysis of the interaction of income inequality and poverty and its effect on health. Soc Sci Med 139:123-131

Regidor E, Santos JM, Ortega P, Calle ME, Astasio P, Martínez D (2014) Decreasing income inequality and emergence of the association between income and premature mortality: Spain, 1970-2010. Health Place 27:30-37

Rodgers GB (1979) Income and inequality as determinants of mortality: an international cross-section analysis. Popul Stud 33(2):343-351

Shaw M, Davey Smith G, Dorling D (2005) Health inequalities and new labour: how the promises compare with real progress. BMJ 30: 1016-1021

Siegel M, Vogt V, Sundmacher L (2014) From a conservative to a liberal welfare state: decomposing changes in income-related health inequalities in Germany, 1994-2011. Soc Sci Med 108:10-19

Siegel M, Mielck A, Maier W (2015) Individual Income, area deprivation, and health: do income-related health inequalities vary by small area deprivation? Health Econ 24(11):1523-1530

Singh GK, Siahpush M (2002) Increasing inequalities in all-cause and cardiovascular mortality among US adults aged 25-64 years by area socioeconomic status, 1969-1998. Int J Epidemiol 31(3): $600-613$

Starfield B (2000) Is US health really the best in the world? JAMA 284: 483-485

Thomas B, Dorling D, Davey Smith G (2010) Inequalities in premature mortality in Britain: observational study from 1921 to 2007 . BMJ 41:C3639

Torre R, Myrskylä M (2014) Income inequality and population health: an analysis of panel data for 21 developed countries, 1975-2006. Popul Stud 68(1):1-13

Vallejo-Torres L, Hale D, Morris S, Viner RM (2014) Income-related inequality in health and health-related behaviour: exploring the equalisation hypothesis. J Epidemiol Community Health 68(7): 615-621

Van Doorslaer EV, Koolman X (2004) Explaining the differences in income-related health inequalities across European countries. Health Econ 13(7):609-628

Van Doorslaer E, Wagstaff A, Bleichrodt H, Calonge S, Gerdtham UG, Gerfin M, Geurts J, Gross L, Häkkinen U, Leu RE, O'Donell O (1997) Income-related inequalities in health: some international comparisons. J Health Econ 16:93-112

Viscusi K (1994) Risk-risk analysis. J Risk Uncertain 8(1):5-17

Wagstaff A, Van Doorslaer E (2000) income inequality and health: what does the literature tell us? Annu Rev Public Health 1:543-567

Waldmann RJ (1992) Income distribution and infant mortality. Q J Econ 107(4):1283-1302

WHO (1986) First international conference on health promotion. WHO, Ottawa

WHO (2008) Commission on social determinants of health. Final report: closing the gap in a generation: health equity trough action on the social determinants of health. WHO, Geneva

Wildman J (2001) The impact of income inequality on individual and societal health: absolute income, relative income and statistical artefact. Health Econ 10:357-361

Wildman J (2003) Modelling health, income and income inequality: the impact of income inequality on health and health inequality. J Health Econ 22:521-538

Wilkinson RG (1992) Income distribution and life expectancy. BMJ 304(6820): 165

Wilkinson RG (1996) Unhealthy societies: the afflictions of inequality. Routledge, London 
Wilkinson RG (1997) Socioeconomic determinants of health. Health inequalities: relative or absolute material standards? BMJ 314(7080):591

Wilkinson RG (1998) Mortality and distribution of income. Low relative income affects mortality. BMJ (Clinical Research ed) 316(7144):1611
Wilkinson RG, Pickett KE (2006) Income inequality and population health: a review and explanation of the evidence. Soc Sci Med 62(7):1768-1784

Wilson KB, Thorpe RJ, LaVeist TA (2017) Dollar for dollar: racial and ethnic inequalities in health and health-related outcomes among persons with very high income. Prev Med 96:149-153 